\title{
CORRECTION
}

\section{Correction to: An analysis of tumor-related skin temperature differences in malignant soft-tissue tumors}

\author{
Akiyoshi Shimatani ${ }^{1}\left[\right.$ [Danabu Hoshi ${ }^{1} \cdot$ Naoto Oebisu $^{1} \cdot$ Naoki Takada $^{1} \cdot$ Yoshitaka Ban $^{1} \cdot$ Hiroaki Nakamura $^{1}$
}

Published online: 17 October 2021

(c) Japan Society of Clinical Oncology 2021

\section{Correction to: International Journal of Clinical Oncology https://doi.org/10.1007/s10147-021-02044-1}

In the original publication Table 4 has been published with incorrect entries. The incorrect and correct entries are given below:

Incorrect entry: $G$ grade (median IQR) 4 [34]

Correct entry: $G$ grade (median IQR) 4 [3-4] [23]

Incorrect entry: Histological grade (median[IQR]) 2

Correct entry: Histological grade (median[IQR]) 2 [2-3]

The corrected version of Table 4 is given in this correction.

The original publication is also corrected.
Table 4 Relationship between clinical data and skin temperature differences $\geq 0.2^{\circ} \mathrm{C}$

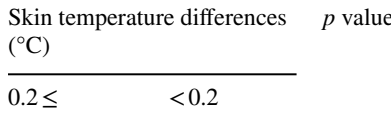

\begin{tabular}{lllc}
\hline Sex $(n)$ & & & 0.85 \\
Men & 28 & 37 & \\
Women & 24 & 29 & \\
Age (years old) & $61.8 \pm 19.4$ & $60.9 \pm 13.8$ & 0.77 \\
Size (cm) & $6.8 \pm 5.3$ & $5.2 \pm 4.3$ & 0.08 \\
Distance (mm) & $5.8 \pm 6.7$ & $9.4 \pm 9.9$ & $0.03 *$ \\
CRP (mg/dL) & $0.6 \pm 1.9$ & $0.5 \pm 1.9$ & 0.7 \\
G grade (median [IQR]) & $4[3-4]$ & $2[1-2]$ & $<0.001^{*}$ \\
Histological grade (median [IQR]) & $2[2-3]$ & $2[1-2]$ & $0.02 *$ \\
\hline
\end{tabular}

Publisher's Note Springer Nature remains neutral with regard to jurisdictional claims in published maps and institutional affiliations.

The original article can be found online at https://doi.org/10.1007/ s10147-021-02044-1.

Akiyoshi Shimatani

bpcip920@tcct.zaq.ne.jp

1 Department of Orthopedic Surgery, Osaka City University

Graduate School of Medicine, 1-4-3 Asahi-Machi,

Abeno-ku, Osaka 545-8585, Japan 